\title{
The effects of cancer care pathways on waiting times
}

Magdalena Smeds and Bozena Bonnie Poksinska

The self-archived postprint version of this journal article is available at Linköping University Institutional Repository (DiVA):

http:// urn.kb.se/ resolve?urn=urn:nbn:se:liu:diva-154049

N.B.: When citing this work, cite the original publication.

Smeds, M., Poksinska, B. B., (2018), The effects of cancer care pathways on waiting times,

International J ournal of Quality and Service Sciences. https:// doi.org/ 10.1108/IJ QSS-04-2018-0041

Original publication available at:

https:// doi.org/ 10.1108/IJ QSS-04-2018-0041

Copyright: Emerald

http:// www.emeraldinsight.com/ 


\title{
The effects of cancer care pathways on waiting times
}

\author{
Magdalena Smeds and Bozena Bonnie Poksinska \\ magdalena.smeds@liu.se; bonnie.poksinska@liu.se \\ Logistics and Quality Management, \\ Linköping University, Linköping, Sweden
}

\begin{abstract}
Purpose - The Swedish health care system currently implements Cancer Care Pathways (CCPs) for better and more timely cancer diagnostics. The aim of this paper is to elucidate and define 'crowding out' effects associated with the CCP implementation.

Design/methodology/approach - A document study based on implementation reports and action plans from Swedish regions $(n=21)$ and a case study in one region were conducted. Qualitative data collection and analysis were used to acquire more knowledge about the 'crowding out' effects associated with the CCP implementation.

Findings - Three effects discussed under 'crowding out' were defined. The first effect, called the push-out effect, occurs when other patients have to wait for care longer in favour of CCP patients. Another effect is the inclusion effect, whereby 'crowding out' is reduced for vulnerable patients due to the standardised procedures and criteria in the referral process. The final effect is the exclusion effect, where patients in need of cancer diagnostics are, for some reason, not referred to CCP. These patients are either not diagnosed at all or diagnosed outside CCP by a non-standard process, with the risk of longer waiting times.

Originality/value - 'Crowding out' effects are an urgent topic related to CCP implementation. While these effects have been reported in international research studies, no shared definition has been established to describe them. The present paper creates a common base to measure the 'crowding out' effects and support further development of CCPs to avoid the negative effects on waiting times.
\end{abstract}

Keywords - Quality Management; Health care; Standardization; Quality of healthcare; Patient care; Health Care Management

Paper type - Research paper

\section{Introduction}

Diagnosing cancer is usually a complex process involving a large number of health care professionals and activities in terms of tests and appointments. Organisational aspects such as the 'silo mentality', resulting from the high specialisation in health care, further contribute to this complexity and lead to fragmented and uncoordinated care processes (Coleman, 2003). The Swedish cancer care also suffers from problems such as long waiting times, regional differences and dissatisfied patients and despite the launch of several improvement programmes, these problems persist (Ministry of Health and Social Affairs, 2015).

In 2015 a new national improvement programme in cancer care was launched. With the Danish model of Pakkeforløb as a base, standardised cancer care pathways (CCPs) have been implemented in all 21 regions in Sweden (NBHW, 2016). The improvement program includes specific diagnostics guidelines for different cancer types, fast-track pathways with prescheduled time slots and introduction of CCP coordinators. The guidelines are designed to facilitate early detection, standardise diagnostic procedures, and set up maximum waiting times. 
The aim is to decrease waiting times and the inequalities both between and within regions, thereby increasing the quality of cancer diagnostics (NBHW, 2015).

The implementation of CCPs is in progress and more and more cancer diagnoses are included. Generally, CCPs are perceived to improve cancer diagnostics and shorten waiting times, but there is a heated debate about negative effects for other patient groups (NBHW, 2016). Prioritising cancer patients and giving them pre-scheduled time slots is perceived to make waiting times longer for other patients. These negative effects are however difficult to identify and prevent since they are not defined, not measured, and linked to various patient groups. In a system like health care, where the different components are highly dependent on each other, it is a well-known problem that focus on improving just one component of the system may lead to negative consequences and sub-optimisation of the entire system (Grol et al., 2013). For example, Lane et al. (2000) conclude in their study that reductions in bed numbers do not increase waiting times for emergency admissions as expected. Instead, the result was the unexpected increase of cancellations of elective surgeries. In Sweden, these kinds of negative effects are discussed under the term 'crowding out'. The term is not only discussed in relation to CCPs, but often debated in relation to patient prioritisation, resource allocation and equitability issues (NBHW, 2016).

In order to prevent undesired negative effects in other parts of the health care system there is a need for common understanding and hard facts about what the 'crowding out' effect means. The aim of this paper is to elucidate and define the 'crowding out' effects associated with CCP implementation. This paper provides a starting point for measuring the 'crowding out' effects and taking preventive actions if results indicate that negative effects occur.

\section{Theoretical framework}

The Swedish health care system is under constant pressure for change. Among the main reasons for this development are the increasing complexity of health care systems, the focus on efficiency and effectiveness, the pressure for cost reduction due to increased care demands, and the development towards more individualised, patient-centred care (Groene et al., 2011). Consequently, there is a trend where health care officials, commissioners, and professionals are striving to find new ways to organise for improved quality of care.

\section{Quality of care in cancer diagnostics}

In 2001, the Institute of Medicine defined quality of care with six underlying requirements: patient-centred, safe, effective, efficient, timely, and equitable. A health care system that achieves major gains in these six areas is believed to be much better at meeting patient needs (Institute of Medicine, 2001). These requirements have been accepted internationally and appear in policy contexts worldwide (Beattie et al., 2013); in Sweden, the definition has been adapted by the National Board of Health and Welfare (NBHW, 2006).

The goal of the CCP implementation is to improve all the requirements of good quality of care. First, the implementation of CCPs implies extending the communication with the patients, thereby increasing patient participation and patient-centeredness. Increased communication with patients has been shown to have a positive effect on patient satisfaction (Kazemi and Kajonius, 2017; Kamra et al., 2016) and better staff responsiveness can lead to better health outcomes (Turan et al., 2016). Second, better coordination and multi-professional cooperation aim to make cancer care safer, more effective and more efficient (Freijser et al., 2015). Third, the standardisation of cancer diagnostics helps to deliver more uniform and predictable diagnostic processes and thereby increase equitability (Håland and Melby, 2016). 
Standardisation with associated reduction of variation is one of the important principles of quality management, which ensures consistency and predictability of work processes and makes the system less dependent on individuals (Deming, 1994; Dahlgaard et al., 2008). Finally, CCP intends to make cancer diagnostics more timely (Jensen, 2015).

Long waiting times are a well-known challenge in most health care systems. Different strategies, for example Lean production, are used to reduce waiting times (Dahlgaard et al., 2011; Kollberg et al., 2006; Poksinska, 2015). Generally, waiting times occur when there are insufficient resources available to satisfy the care needs. Variation in patient inflow contributes to mismatch in capacity and demand and thereby generates queues or creates an underuse of resources (Silvester et al., 2004; Murray and Berwick, 2003). The relationship between waiting times and ineffectiveness in health care delivery, patient dissatisfaction and increased suffering for patients are among the reasons why it is important to measure and follow up waiting times (Viberg et al., 2013). Research also shows that comparisons and monitoring of health care quality and efficiency, such as waiting times, encourages improvements and striving for improved results over time (Elg et al., 2012; Langley et al., 2009).

Effects on waiting times from the system perspective

Understanding the system and the interrelatedness of its components is an underlying condition for improvement of a system (Deming, 1994). Since health care is characterised as a complex system (Plsek and Greenhalgh, 2001), the interrelatedness of its components is not always straightforward and the consequences of changing the system are not easy to predict (Kannampallil et al., 2011; Grol et al., 2013). CCP is a care pathway that frequently incorporates several caregivers from different specialist units. Those units not only deliver care to cancer patients, but may also serve several patient groups and provide a wide range of care services. Prioritising and reallocating resources to one patient group may therefore lead to undesired effects. The implementation of CCPs in Sweden is not a new approach and has been implemented in other health care systems before. Denmark implemented CCPs in 2008, which led to decreased waiting times for cancer patients (Larsen et al., 2013), but increased waiting times for other patient groups that were not investigated for cancer (Probst et al., 2012). In the United Kingdom, two-week wait clinics for cancer diagnostics were introduced for breast cancer. Potter at al. (2007) identified that two-week wait referrals for high-risk patients did not capture more cancer as anticipated, but instead extended the waiting times for patients with low risk who turned out to actually have cancer. Hamilton (2009) reported similar results, where patient groups with low risk or vague symptoms risked having to wait longer in favour of highrisk groups.

A study of the Swedish Health Care Guarantee - an improvement programme aimed at decreasing care queues - mentions 'crowding out' effects in the entire health care system, from primary to specialised care. One reason for these effects was the encouragement of prioritising patients coming in for their first visit instead of calling in patients in need of follow-ups. Simple, quick and measurable treatments were prioritised over more complicated actions. This benefits strong patient groups but negatively affects older, multimorbid and chronic patients. The report also mentions that there is no data available to analyse the extent of the 'crowding out' effects (Högrell, 2012).

\section{Method}

This paper is based on a document study of implementation reports from 21 regions and one case study in the Region of Östergötland. 


\section{Document study}

In the document study we analysed how 'crowding out' effects linked to the CCP implementation were described. The Swedish health care system is divided into 21 regions that are responsible for health care provision and management with independent budgets. All regions participate in the implementation of CCPs in their regional health care systems and are obligated to submit annual action plans and result reports to the NBHW. The content of the reports is partly specified by NBHW and information is collected in part about the challenges and risks connected to undesired effects.

We collected, read and analysed all reports and action plans from 2015-2017, which are available online at the Regional Cancer Centre in Cooperation (RCCC) website. The analysis of the material was conducted through a combination of a systematic word search and theme categorisation (Bryman, 2003). Before the analysis started, the authors read previously published reports from for example the NBHW related to 'crowding out' effects and decided on some search terms. These terms - crowding out, inclusion, effect, risk, waiting, lead-time, and equitability - were used for an initial content search in the reports. Relevant data were compiled into a document and an initial categorisation was made. Afterwards, all documents were thoroughly read through to ensure no effects were missed. All regions were assigned a letter (Table I), which was used for referencing in the presentation of the empirical data.

\section{$<$ Insert table 1 here $>$}

\section{Case study}

The case study was conducted in the Region of Östergötland in Sweden, which started implementing CCPs in 2015. The aim was to gain more understanding about the phenomena under investigation in their natural setting (Bryman, 2003; Yin, 1989). The case study had a dual purpose. The first part was to gain knowledge about the implementation of CCPs and identify determinants enabling and/or hindering the implementation. The second purpose most relevant for the present study - was to understand the anticipated effects of the CCP implementation. The complete case study was presented in a master's thesis (Smeds, 2016).

The data collection methods included a document study, mapping of patient pathways, interviews and participant observations (Patton, 2002; Bryman, 2003). The document study was based on internal reports and documents primarily written by the Region of Östergötland and the South East Regional Cancer Centre about the CCP implementation and other related improvement projects in cancer care. Mapping of patient pathways based on the medical record system was used to identify health care professionals working with CCPs in different parts of the diagnostic process. The aim of this step was to ensure that health care professionals invited for interviews had experience with CCP. Sixteen semi-structured interviews (Kvale, 1996) were conducted with seven nurses, three physicians, two care unit managers, two general practitioners and two regional project leaders for the CCP implementation. The selection of the respondents aimed at getting the experience of medical professionals with different backgrounds and working in different organisational units (Kvale, 1996). One part of the interviews focused on the health care professionals' perceptions of anticipated risks and effects due to the CCP implementation. If the interviewees did not mention 'crowding out' effects, the interviewer deliberately raised the subject. Examples of questions were: How does the scheduling of appointments work? How are the scheduled times utilised? How do you think the pre-scheduled time slots affect patients? What are your thoughts on 'crowding-out' effects in relation to CCPs? The length of the interviews varied from 45-120 minutes depending on the 
respondent's knowledge about CCPs. All interviews were recorded and transcribed to ensure accuracy in data analysis (Kvale, 1996).

Finally, observations of meetings $(n=10)$ were conducted. A combination of both participant and non-participant method was used (Patton, 2002). The participant observations were done on planning and development meetings related to CCP implementation. The non-participant observations were done on multidisciplinary conferences to gain a deeper understanding about the working methods and decision-making processes of health care professionals. The observation time varied between 1-3 hours. Unstructured field notes were taken during observations and compared between both researchers to ensure no content was missed (Bryman, 2003).

The data were analysed using qualitative content analysis. The various data collection techniques were used to ensure the validity of the research findings (Patton, 2002).

\section{Result}

In the following section, we first outline the reasons why 'crowding out' effects occur in relation to CCP implementation. We then define the different effects under the term 'crowding out'. We illustrate the effects by describing hypothetical situations involving patients.

Reasons for 'crowding out' effects

Table II shows a summary of the reasons for 'crowding out' effects with reference to regions. The identified reasons are the increased number of cancer diagnostics, lack of capacity, and pre-scheduled appointments, which are further described in this section.

$<$ Insert table 2 here $>$

The first reason for the occurrence of 'crowding out' effects is the potentially increased number of cancer diagnostics. Before CCP implementation, patients were frequently referred to incorrect specialised care units, or not referred at all, due to vague or unclear symptoms. The introduction of standardised criteria for cancer referral was supposed to solve this problem. The general expectation was an unchanged number of patients in need of cancer diagnostics but an increased possibility of early detection. Despite this, the flow of patients being referred for cancer diagnostics into some CCPs is perceived to have increased in several regionss. One reason for this appears to be that the broad criteria capture a larger number of patients who turn out not to have cancer. More patients need to be prioritised and handled within the maximum waiting time limits. This may imply longer waiting times for other patients in need of the same resources and thereby lead to 'crowding out' effects. A risk was also perceived that physicians could misuse the CCP referral to get their non-cancer patients through fast-track diagnostics. Patients not in urgent need of care get their tests and examinations faster and contribute to longer waiting times for patients in greater need of care.

The second reason for the occurrence of 'crowding out' effects is the lack of capacity. Uneven resource allocation, understaffing and lack of capacity are huge challenges throughout the Swedish health care system, and are not new phenomena related to CCP implementation. The maximum waiting times are perceived to add extra pressure to the system, making some regions worried about being able to keep the maximum waiting times with the scarce resources. The lack of competence and capacity appear to be greatest in radiology, pathology, urology, endoscopy and surgery units, which risk leading to queues and long waiting times.

The third reason is pre-scheduled appointments. CCP implies a new procedure of opening up pre-scheduled timeslots for CCP patients. This way, appointments are prioritised for CCP patients and ensure availability within the maximum waiting times. Unused timeslots are a 
waste of resources in an already congested schedule and risk leading to longer waiting times for all patients. To minimise this risk, some regions have increased the flexibility in the scheduling system by setting up procedures for when the pre-scheduled timeslots can be booked for other patient groups.

Effects described under 'crowding out'

Table III summarises the effects identified in the empirical material with references to regions.

$<$ Insert table 3 here $>$

First, the CCP implementation may imply longer waiting times for patients with non-cancer diseases, which can be illustrated by the following example:

Hannah went to the GP because of her stomach problems. The GP suspected a celiac disease and referred her to specialised care. She was placed on the waiting list and had to wait 2.5 months to see the physician and two additional months to receive her colonoscopy, because CCP patients were prioritised.

Longer waiting times for patients with non-cancer diseases is the most frequently mentioned risk after CCP implementation. Patients like Hannah, who seek care for symptoms that do not indicate cancer, are in need of the same resources as cancer patients and therefore risk being set aside to prioritise patients going through a fast-track CCP. Key functions like radiology and pathology have a special need for prioritisation since optimisations with a focus on a single patient pathway risks leading to inequitable resource allocation between patient groups.

The risk groups are patients with more and less serious diseases. Often mentioned are patients with comorbidity, chronic diseases and hospitalised patients, who are often seriously ill and in need of timely and further adequate care. Another example are patients who do not yet show alarm symptoms for cancer but are in need of screening because of their inherited predisposition to cancer.

The second effect described under 'crowding out' is longer waiting times for patients with cancer and going through cancer diagnostics. The example below illustrates the situation.

Martin is 80 years old, was treated for and cured of bladder cancer two years ago, and requires regular follow-ups. Sophie is a 50-year-old woman in overall good health. She was referred to the urology clinic with suspicion of bladder cancer due to findings of blood in the urine. Sophie got an appointment within one week. Even though it was time for Martin to get a follow-up appointment, he needed to wait two months longer because CCP patients were prioritised.

The example above illustrates a 'crowding out' effect for patients who require follow-up visits. The need for follow-ups generally increases in health care due to higher survival rates and patients growing older. Prioritising CCP patients may lead to longer waiting times for followups since the medical need, as in Martin's case, is perceived to be lower for this patient group. However, follow-ups are important in order to find patients who suffer relapses of cancer. There has been a national discussion about how to handle relapse patients within CCPs. The discussion is whether they should start a new CCP and receive CCP priority or not.

Prioritisations are needed throughout the cancer care process to ensure that the resources are used in the best possible way in every situation. Medical need should be the main discriminating factor to prioritise among CCPs and among individual patients. Due to under-capacity of appointments and treatments in many regions, there are challenges in ensuring all patients fall 
within the maximum waiting times. After implementing CCPs there is a risk that patients who are getting close to the maximum waiting times are prioritised over other patients. This counteracts the medical need for prioritisation but ensures that patients receive care within the maximum waiting times. There is also a paradox for patients who are first quickly diagnosed through CCP but then have to wait a long time for treatment due to, for example, queues for surgery.

The third effect is 'crowding out' from CCPs due to serious illness, as described in the example below:

Karl is 93 years old, multimorbid, has a hard time moving around on his own and lives in a nursing home. In the last few weeks, Karl has lost a lot of weight, has little appetite and gets heartburn. His GP suspects that he might have stomach cancer but has decided that Karl should be diagnosed for cancer outside a CCP. Due to his fragile condition, Karl is considered unable to make the investigations within the set maximum waiting times or fit into a fast -track diagnostic pathway.

Very sick or old patients like Karl with complex care needs might be considered unsuitable to follow a standardised process. Going through a CCP means that the patient should be completing diagnostics within the maximum waiting times and going through the predetermined activities in a timely manner. This might not work for some patients due to their severe health condition, medications or the fact that they do not benefit from being pushed through the diagnostics process. These patients are referred for cancer diagnostics outside the CCP.

There is a serious problem if patients are referred to CCP based on whether they are able to meet the maximum waiting times, rather than their medical need. A patient who is believed to be a demanding diagnostic case might be referred outside the CCP and thus is deprived of a faster diagnostic pathway. This also provides a skewed image of what kinds of patients go through CCPs and how long a cancer diagnostic process actually is.

The fourth effect is 'crowding out' due to socio-demographic attributes, which can be illustrated as follows:

Dave is a 35-year-old mentally ill wheelchair user who is aided by an assistant throughout the day. Because of a last-minute cancellation, an appointment is made available at the clinic in a few hours. Even though Dave is the next person on the waiting list, he is not brought in because he is considered unable to attend his appointment due to his special assistant needs.

Patients such as older patients, addicts, patients in need of an interpreter, patients with disabilities or mental diseases, are categorised as vulnerable patient groups. Patients like Dave risk not being referred to CCPs or being delayed in diagnostics due to reasons such as need for special assistance, incomprehension or inability to take an active role in the diagnostic process, and they risk having to stand back in favour of patients who are more forceful. Even though neither these difficulties nor patient groups are new to health care, they are believed to become visible in relation to CCPs when the focus is on meeting the maximum waiting times.

The fifth effect is positive and implies reduction of 'crowding out' due to standardised criteria for referral.

Maria is a 47-year-old unemployed alcoholic living on social support. She has been feeling unwell for some time but is afraid to seek care. She collapsed on the street and was brought by 
ambulance to the emergency department. Maria did not want to make any trouble and explained that everything is just because of her alcohol problem. At first, the emergency physician felt the same way, but after hearing about the symptoms decided to refer Maria to CCP since she fulfilled the criteria for severe non-specific symptoms that indicate cancer.

The introduction of standardised criteria for referral has increased the chance of finding and treating patients who previously risked being delayed in their cancer diagnosis due to being 'stuck' in primary care, being unable to speak for themselves or following a random diagnostic process. One example is patients, like Maria, with unclear symptoms, who now go straight into cancer diagnostics instead of being referred by physicians through trial and error to different units of the health care system.

\section{Discussion}

The implementation of CCPs aims to contribute to more patient-centred, safe, effective, efficient, timely, and equitable care. This paper shows that the regions anticipate several effects that influence the quality of cancer diagnostics, but also mention undesired effects in other parts of the health care system.

The deeper analysis of 'crowding out' effects revealed that we are actually talking about three different effects; we labelled these the push-out effect, inclusion effect and exclusion effect. Figure 1 shows an overview of the effects of CCP implementation associated with 'crowding out' effects.

$<$ Insert figure 1 here $>$

A push-out effect is an unintended and undesired side effect of CCP implementation on waiting times. This is in line with other research showing that a quality improvement initiative in one part of the health care system may have negative, unintended consequences for quality and efficiency in other parts of the system (Grol et al., 2013). The main objective for Swedish health care, as expressed in the Health Care Act (1982), is good health care on equal terms for the entire population. Prioritisations should be made according to the ethical platform and not be influenced by personal characteristics, societal status, etc. According to this act push-out effects occur when:

Patients with lower priority (lower medical need) receive care before patients with higher priority (greater medical need). (NBHW, 2016)

This definition indicates that waiting longer is not s sufficient criterion and the push-out effect first occurs when the medical prioritisation has been set aside (NBHW, 2016). The pushout effects in relation to CCP were stated in the literature before (Larsen et al., 2013; Probst et al., 2012; Hamilton, 2009), but not deliberately discussed with respect to prioritisation and medical need. Cancer patients have a high priority due to the severity of the illness; if patients with lower priority have to wait longer, a push-out effect does not occur according to the definition. The push-out effect occurs for patients who have the same priority as cancer patients, as for example patients diagnosed and treated for cancer outside CCPs or patients with equally serious or more serious diseases and conditions. Push-out effects may also occur for vulnerable patient groups. Focus on meeting the maximum waiting times combined with the lack of capacity and personnel resources in specialist care may disadvantage those patients due to their special needs, such as the need for an interpreter or the inability to transport themselves. Stronger patients may have shorter waits due to their higher ability to take any available time 
for investigation or visit offered to them. All regions mention some kind of problem with available resources or capacity, which means that conscious prioritisation needs to be made in order to avoid push-out effects.

One of the goals with CCPs is to make cancer care more equitable. All patients in need of cancer care should receive care that does not vary in quality due to personal characteristics such as gender, ethnicity, geographic location, and socioeconomic status. Before the introduction of CCPs, patients risked being consciously or unconsciously excluded from cancer diagnostics due to such factors as unspecific symptoms, low socio-economic status, disabilities, age or language barrier. These patients are often less inclined to fight for their right to be diagnosed and treated and might therefore have waited longer or been excluded from cancer diagnostics. Van Doorslaer et al. (2006) studied inequalities in access to medical care and found that people with higher incomes are significantly more likely to see a specialist than people with lower incomes. There are some indications in our results that CCPs might have changed the situation. Standardised criteria for referral are believed to create the inclusion effect, meaning that more patients from vulnerable patient groups are included now in cancer diagnostics.

Finally, an exclusion effect can take place. Not all patients might be considered suitable to follow CCPs or are willing to follow a CCP. The patient's age, medical history, comorbidity, disabilities and need for special support could be among the factors that hinder patients to follow CCPs. For example, a patient with bad health conditions might not be able to make the necessary investigations within the maximum waiting time limits and might be excluded from CCP.

Defining the 'crowding out' effects sets an important foundation with which to measure the effects, prevent the risks associated with push-out effects, and improve the situation for patients suffering from the exclusion effect. Real data on patient flow and waiting times need to be collected from patient record and national monitoring systems. The authors of this paper work currently on a study of measuring the 'crowding out' effects for urology patients. Three patient groups (prostate, bladder cancer and kidney stone) that share the same resources will be analysed. The examples of how the three types of effects can be measured follow:

- The inclusion effect is investigated by comparing the sociodemographic distribution of patients before and after CCP introduction. We aim to analyse if more patients are diagnosed for prostate and bladder cancer before and after CCP introduction and what is the quota of number of detected cancers in relation to number of patients diagnosed.

- The exclusion effect is investigated by testing if there are significant differences in the sociodemographic distribution of patients referred to CCP compared to patients not referred to CCP. For example, are fewer older, multimorbid patients referred to CCP compared to younger and healthier patients?

- For the push-out effect we plan to investigate if the waiting times for kidney stone patients got longer after the implementation of CCP. Kidney stone patients are a relatively highly prioritised patient group, for which longer waiting times are not desirable.

\section{Conclusions}

This paper elucidated and defined 'crowding out' effects associated with the implementation of CCPs in the Swedish health care system. Our results show that the notion of 'crowding out' actually comprises three different types of effects related to waiting times and equitability issues: push-out effect, inclusion effect and exclusion effect. A push-out effect occurs when patients with the same or higher medical need have to wait longer because CCP patients are prioritised in the health care system. An inclusion effect occurs when patients from vulnerable groups who were previously delayed or excluded are now, due to CCPs, referred to more timely 
cancer diagnostics. Finally, an exclusion effect occurs when a patient is not referred to CCPs due to his or her health status or special needs.

The major theoretical contribution of the paper is a conceptualisation of effects discussed under 'crowding out'. Although these effects are not a new phenomenon in health care, there is a lack of common definitions and terminology and a corresponding lack of standard protocols for measuring them. 'Crowding out' is generally associated with negative effects on waiting times, but as our results show 'crowding out' may also imply both positive and negative effects related to the equitability of care. This paper also points to the importance of system thinking in health care. As we have shown, improvements in one part of the system may have negative consequences in other parts of the system.

The practical contribution is setting a common base for measuring the 'crowding out' effects of CCPs in the Swedish health care system. The widely discussed negative effects of CCP implementation on waiting times are only one of the effects associated with 'crowding out', and those are actually not as negative as perceived. According to the Swedish Health Care Act longer waiting times, although undesired, do not always mean that a push-out effect has occurred. The negative effects on waiting time need to be evaluated in relation to the medical prioritisation of patients. If an inclusion effect occurs, i.e., more patients from vulnerable groups are diagnosed with cancer, longer waiting times for patients with lower priority are not as bad as perceived. The limited health care resources need to be allocated in a fair, equitable manner. In this respect, it is important to pay more attention to exclusion effects as they violate the underlying principle of providing good health care on equal terms for the entire population.

\section{Disclosure statement}

No potential conflict of interest was reported by the authors.

\section{References}

Beattie, M., Shepherd, A. \& Howieson, B. (2013) Do the Institute of Medicine’s (IOM's) dimensions of quality capture the current meaning of quality in health care?-An integrative review. Journal of Research in Nursing, 18(4), pp. 288-304.

Bryman, A. (2003) Quantity and quality in social research, New York: Routledge.

Coleman, E. A. (2003) Falling through the cracks: challenges and opportunities for improving transitional care for persons with continuous complex care needs. Journal of the American Geriatrics Society, 51(4), pp. 549-555.

Dahlgaard, J. J., Kanji, G. K. \& Kristensen, K. (2008) Fundamentals of total quality management, New York: Routledge.

Dahlgaard, J. J., Pettersen, J. \& Dahlgaard-Park, S. M. (2011) Quality and lean health care: A system for assessing and improving the health of healthcare organisations. Total Quality Management \& Business Excellence, 22(6), pp. 673-689.

Deming, W. E. (1994) The New Economics for Industry, Government, Education, Massachusetts Institute of Technology.

Elg, M., Engström, J., Witell, L. \& Poksinska, B. (2012) Co-creation and learning in health-care service development. Journal of Service Management, 23(3), pp. 328-343.

Freijser, L., Naccarella, L., Mckenzie, R. \& Krishnasamy, M. (2015) Cancer care coordination: building a platform for the development of care coordinator roles and ongoing evaluation. Australian Journal of Primary Health, 21, pp. 157-163.

Groene, O., Mora, N., Thompson, A., Saez, M., Casas, M. \& Suñol, R. (2011) Is the maturity of hospitals' quality improvement systems associated with measures of quality and patient safety? BMC Health Services Research, 11(344), pp. 1-11.

Grol, R., Wensing, M., Eccles, M. \& Davis, D. (eds.) (2013) Improving Patient Care: The Implementation of Change in Health Care, Chichester: John Wiley \& Sons. 
Håland, E. \& Melby, L. (2016) Individualised standardisation? Articulating cancer care through standardised patient pathways. BSA MedSoc Conference. University of Aston, Birmingham, UK.

Hamilton, W. (2009) Five misconceptions in cancer diagnosis. Br J Gen Pract, 59, pp. 441-447.

Högrell, O. (2012) Medicine now? Suggestion for more equitable care guarantee - a dicussion paper [In Swedish]. Sveriges Läkarförbund.

Institute of Medicine (2001) Crossing the Quality Chasm: A New Health System for the 21st Century, Washington, DC: National Academy Press.

Jensen, H. (2015) Implementation of Cancer Patient Pathways and the Association with More Timely Diagnosis and Earlier Detection of Cancer Among Incident Cancer Patients in Primary Care. PhD Dissertation, Aarhus University.

Kamra, V., Singh, H. \& Kumar De, K. (2016) Factors affecting patient satisfaction: an exploratory study for quality management in the health-care sector. Total Quality Management \& Business Excellence, 27(9-10), pp. 1013-1027.

Kannampallil, T. G., Schauer, G. F., Cohen, T. \& Patel, V. L. (2011) Considering complexity in healthcare systems. Journal of Biomedical Informatics, 44(6), pp. 943-947.

Kazemi, A. \& Kajonius, P. (2017) Variations in user-oriented elderly care: a multilevel approach. International Journal of Quality and Service Sciences, 9(2), pp. 138-147.

Kollberg, B., Dahlgaard, J. J. \& Brehmer, P.-O. (2006) Measuring lean initiatives in health care services: issues and findings. International Journal of Productivity and Performance Management, 56(1), pp. 7-24.

Kvale, S. (1996) InterViews. An introduction to Qualitative Research Interviewing, Thousand Oaks, CA: SAGE Publications.

Lane, D. C., Monefeldt, C. \& Rosenhead, J. V. (2000) Looking in the wrong place for healthcare improvements: A system dynamics study of an accident and emergency department. Journal of the Operational Research Society, 51(5), pp. 518-531.

Langley, G. J., Moen, R. D., Nolan, K. M., Nolan, T. W., Norman, C. L. \& Provost, L. P. (2009) The improvement guide: a practical approach to enhancing organizational performance, John Wiley \& Sons.

Larsen, M. B., Hansen, R. P., Hansen, D. G., Olesen, F. \& Vedsted, P. (2013) Secondary care intervals before and after the introduction of urgent referral guidelines for suspected cancer in Denmark: a comparative before-after study. BMC Health Services Research, 13(348), pp. 1-9.

Ministry of Health and Social Affairs (2015) Shorter waiting times in cancer care. Agreement between the government and Swedish Association of Local Authorities and Regions 2015 [In Swedish]. Stockholm.

Murray, M. \& Berwick, D. M. (2003) Advanced access: reducing waiting and delays in primary care. JAMA, 289(8), pp. 1035-1040.

NBHW (2006) Good quality of care - management system for quality and patient safety in health care [In Swedish]. Stockholm.

NBHW (2015) Standardised cancer patient pathways. Progress report 2015 [In Swedish]. Stockholm.

NBHW (2016) Standardised cancer patient pathways. Progress report 2016 [In Swedish]. Stockholm.

Obert, C. \& Forsell, C. (2000) Fokusgrupp - ett enkelt sätt att mäta kvalitet, Höganäs, Kommunlitteratur.

Patton, M. Q. (2002) Qualitative research and evaluation methods, Thousand Oaks, CA: Sage Publications.

Plsek, P. E. \& Greenhalgh, T. (2001) The challenge of complexity in health care. BMJ: British Medical Journal, 323(7313), pp. 625-628.

Poksinska, B. (2015) Lean Healthcare: What Is the Contribution to Quality of Care? In: Örtenblad, A., Löfström, C. A. \& Sheaff, R. (eds.) Management Innovations for Health Care Organizations: Adopt, Abandon or Adapt? New York: Routledge.

Potter, S., Govindarajulu, S., Shere, M., Braddon, F., Curran, G., Greenwood, R., Sahu, A. K. \& Cawthorn, S. J. (2007) Referral patterns, cancer diagnoses, and waiting times after introduction of two week wait rule for breast cancer: prospective cohort study. BMJ, 335(288), pp. 288-290. 
Probst, H. B., Hussain, Z. B. \& Andersen, O. (2012) Cancer patient pathways in Denmark as a joint effort between bureaucrats, health professionals and politicians-A national Danish project. Health Policy, (105), pp. 65-70.

Silvester, K., Lendon, R., Bevan, H., Steyn, R. \& Walley, P. (2004) Reducing waiting times in the NHS: is lack of capacity the problem? Clinician in Management, 12(3), pp. 105-109.

Smeds, M. (2016) Implementation of standardized patient pathways: A shortcut into cancer care [In Swedish]. Master's thesis. Linköping University.

Turan, A., Turan, A., Bozaykut-Bük, T. \& Bozaykut-Bük, T. (2016) Analyzing perceived healthcare service quality on patient related outcomes. International Journal of Quality and Service Sciences, 8(4), pp. 478-497.

Van Doorslaer, E., Masseria, C., Koolman, X. \& Group, O. H. E. R. (2006) Inequalities in access to medical care by income in developed countries. Canadian Medical Association Journal, 174(2), pp. 177-183.

Viberg, N., Forsberg, B. C., Borowitz, M. \& Molin, R. (2013) International comparisons of waiting times in health care-Limitations and prospects. Health Policy, 112(1), pp. 53-61.

Yin, R. K. (1989) Case study research: Design and methods, Newbury Park, CA: Sage Publications. 


\section{Appendix: Tables and figures}

Table I: List of the regions with the assigned letter.

\begin{tabular}{cl|cl|cl} 
Letter & Region & Letter & Region & Letter & Region \\
\hline C & Uppsala & K & Blekinge & W & Dalarna \\
D & Sörmland & M & Skåne & X & Gävleborg \\
E & Östergötland & N & Halland & Y & Västernorrland \\
F & Jönköpings län & O & Västra Götaland & Z & Jämtland, \\
G & Kronoberg & S & Värmland & AB & Stockholm \\
H & Kalmar & T & Örebro län & AC & Västerbotten \\
I & Gotland & U & Västmanland & BD & Norrbotten \\
\hline
\end{tabular}

Table II: Reasons for 'crowding out' effects.

\begin{tabular}{lll}
\hline Reason & Affected & CC or Region \\
\hline $\begin{array}{l}\text { Increased number of } \\
\text { cancer diagnostics }\end{array}$ & In general & C,D,E,H,I,T,X,Y,AB,AC,BD \\
\hline Lack of capacity & In general & $\begin{array}{l}\text { C,D,E,F,G,H,I,K,M,N,O,S,T,U, } \\
\text { W,X,Y,Z,AB,AC,BD }\end{array}$ \\
\cline { 2 - 3 } & Radiology & $\mathrm{C}, \mathrm{D}, \mathrm{F}, \mathrm{G}, \mathrm{I}, \mathrm{K}, \mathrm{M}, \mathrm{O}, \mathrm{S}, \mathrm{T}, \mathrm{W}, \mathrm{X}, \mathrm{Y}, \mathrm{AB}, \mathrm{AC}, \mathrm{BD}$ \\
\cline { 2 - 3 } & Pathology & $\mathrm{C}, \mathrm{D}, \mathrm{G}, \mathrm{H}, \mathrm{I}, \mathrm{M}, \mathrm{O}, \mathrm{S}, \mathrm{T}, \mathrm{W}, \mathrm{X}, \mathrm{Y}, \mathrm{AB}, \mathrm{AC}$ \\
\cline { 2 - 3 } & Urology & $\mathrm{C}, \mathrm{E}, \mathrm{F}, \mathrm{G}, \mathrm{I}, \mathrm{K}, \mathrm{M}, \mathrm{N}, \mathrm{O}, \mathrm{S}, \mathrm{T}, \mathrm{W}, \mathrm{X}, \mathrm{Y}, \mathrm{Z}, \mathrm{AB}, \mathrm{AC}, \mathrm{BD}$ \\
\cline { 2 - 3 } $\begin{array}{l}\text { Pre-scheduled } \\
\text { appointments }\end{array}$ & $\mathrm{D}, \mathrm{F}, \mathrm{H}, \mathrm{I}, \mathrm{M}, \mathrm{N}, \mathrm{S}, \mathrm{T}, \mathrm{X}, \mathrm{BD}$ \\
\hline
\end{tabular}


Table III: Overview of effects.

\begin{tabular}{|c|c|c|}
\hline Effect & Affected & CC or Region \\
\hline \multirow{4}{*}{$\begin{array}{l}\text { Longer waiting times for } \\
\text { patients with non-cancer } \\
\text { diseases }\end{array}$} & $\begin{array}{l}\text { Other patient groups in } \\
\text { general }\end{array}$ & C,D,E,G,I,K,M,O,S,U,W,X,Y,Z,AB,AC,BD \\
\hline & $\begin{array}{l}\text { Serious illness or multi- } \\
\text { morbid }\end{array}$ & T,Y,Z,AC,BD \\
\hline & Chronic & $\mathrm{K}, \mathrm{M}, \mathrm{Y}, \mathrm{Z}, \mathrm{AC}, \mathrm{BD}$ \\
\hline & $\begin{array}{l}\text { Patients in need of cancer } \\
\text { screening }\end{array}$ & $\mathrm{O}, \mathrm{S}, \mathrm{AB}$ \\
\hline \multirow{7}{*}{$\begin{array}{l}\text { Longer waiting times for } \\
\text { patients with cancer or } \\
\text { diagnosed for cancer }\end{array}$} & $\begin{array}{l}\text { Patients within 'the same' } \\
\text { CCP }\end{array}$ & $\mathrm{E}, \mathrm{F}, \mathrm{Y}, \mathrm{AB}, \mathrm{AC}, \mathrm{BD}$ \\
\hline & $\begin{array}{l}\text { Patients within different } \\
\text { CCPs }\end{array}$ & E,AC \\
\hline & $\begin{array}{l}\text { First visits and doctors' } \\
\text { appointments }\end{array}$ & O,T,U,BD \\
\hline & Later parts of CCPs & K,U,W \\
\hline & $\begin{array}{l}\text { Quick diagnostics, but long } \\
\text { wait for treatment }\end{array}$ & $\mathrm{E}$ \\
\hline & Follow-up visits & E,F,I,K,M,O,S,U,W,Y,Z,AB,AC,BD \\
\hline & $\begin{array}{l}\text { Follow-up visits for patients } \\
\text { with risk for relapses }\end{array}$ & K,M,S,U,W,AB \\
\hline $\begin{array}{l}\text { 'Crowding out' from } \\
\text { CCPs due to serious } \\
\text { illness }\end{array}$ & $\begin{array}{l}\text { Patients with serious illness } \\
\text { outside of CCPs }\end{array}$ & E,F,W,H \\
\hline $\begin{array}{l}\text { 'Crowding out' due to } \\
\text { sociodemographic } \\
\text { attributes }\end{array}$ & Vulnerable patient groups & E,F,O,X,Y,AC,BD \\
\hline $\begin{array}{l}\text { Reduction of 'crowding } \\
\text { out' due to standardised } \\
\text { criteria for referral }\end{array}$ & Vulnerable patient groups & $\mathrm{E}, \mathrm{W}$ \\
\hline
\end{tabular}

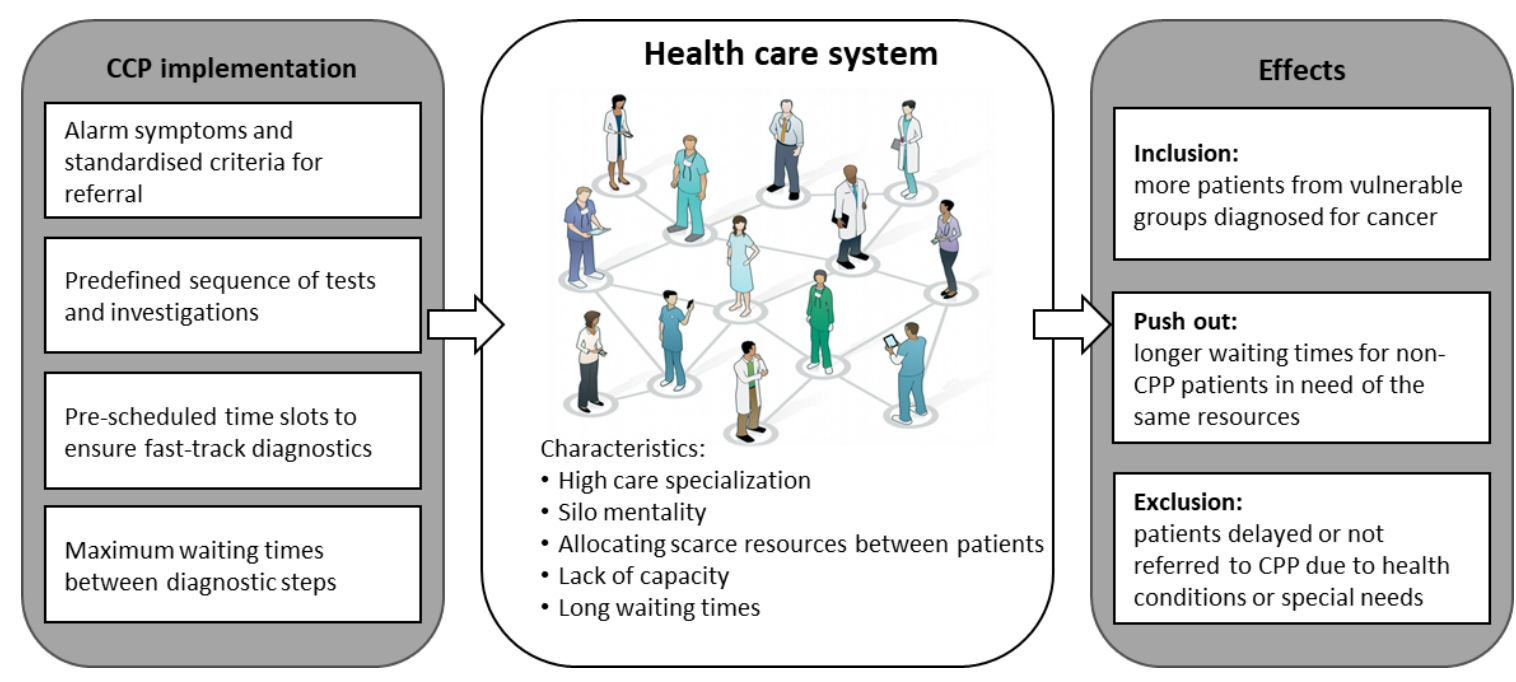

Figure 1: Effects of CCP implementation associated with 'crowding out'. 